\title{
APPLICATION OF GIS TECHNOLOGY FOR TOURISM FLOW MODELLING IN THE UNITED KINGDOM
}

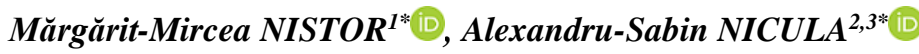

DOI: 10.21163/GT_2021.161.01

\begin{abstract}
:
The fluctuation of tourism flow and its cartographic representation are crucial for transport companies, accommodation and regional tourism, but also for the future modelling of international tourism flow. The origin of tourists and their number represent the most important aspect in tourism flow mapping, which are recorded in statistical databases. One of the most popular and easiest way to obtain tourism flow maps is the Kernel Density function, available on ArcGIS, which uses the vector lines data and density mathematical function to represent the objects' characteristics at spatial scale. Spatial distribution of the tourist flow is a tool to observe and assess the origin and destination countries at spatial scale. In this paper, the modelling of tourist flow from their countries of origin to the United Kingdom (UK) was completed through Geographical Information Systems (GIS) considering four types of visitors. The analysis is based on flow lines and Kernel Density using 48 countries of tourists' source related to 2015. The high and very high densities were found in European countries, US, Australia, China, and Canada. Considering the types of visits, the higher number of tourists during 2015 is in respect with holiday visits (> 1.8 million). The model proposed in this paper and the original maps contribute to future strategies and plans for the international tourism over UK.
\end{abstract}

Key-words: Spatiality, Flow models, International visits, GIS technology, United Kingdom.

\section{INTRODUCTION}

For a better management of tourist arrivals and visits, mainly at spatial scale, the flow models contribute to the understanding of the relationship between tourists' origin and their destination. Once tourist flow and intensity for each direction are known, additional decisions can be taken (e.g. special tourism packages for that countries, improve the flights and transports, political agreement for visas etc.). In this study, the flow model of the holiday visits, business visits, friend's visits, miscellaneous visits, and total visits in UK during 2015 was used to generate the tourism flow modelling.

The study of tourist flow study has a significant role in policy-making decisions and further improvements regarding transports, hotel infrastructure, and touristic sight preparation taking into account the type of tourists, their country of origin, and type of visits. In UK, the main visits are focused on the holiday purpose, followed by business visits, friends visit, and others or/and mixed of these types, therefore defined as miscellaneous visits. In order to have an exhaustive idea about tourism phenomena and to easier analyse tourism data, various software and statistical programs are used. In addition, scientists process such data and contribute to different kind of models, such as gravity models, spatial clustering, econometric regression etc. Thus, several statistical and regression models were implemented and applied in tourism up to present.

Divisekera (2003) developed a demand model for international tourism based on the consumer theory in the US, UK, Japan, and New Zealand demands in Australia. He used the class of preferences called 'Price Independent Generalized Log-Linear' for market demands and including the preferences as minimum expenditure necessary to attain a specific utility at given prices.

\footnotetext{
${ }^{1}$ Earthresearch Company, Department of GIS and Cartography, Cluj-Napoca, Romania: renddel@yahoo.com

${ }^{2}$ National Institute for Economic Research "Costin C. Kiritescu" of the Romanian Academy/Centre for Mountain Economy (CE-MONT): sabin.nicula@gmail.com

${ }^{3}$ Faculty of Geography, University of Babeş-Bolyai, Cluj-Napoca, Romania

*Corresponding author: Mărgărit-Mircea Nistor: rendddel@yahoo.com,

Alexandru-Sabin Nicula : sabin.nicula@gmail.com
} 
Peng et al. (2014) conducted a meta-analysis of international tourism demand elasticities, by reviewing 195 studies published between 1961-2011. The authors examined the relationship between estimated international tourism demand elasticities and the data characteristics and study features that may affect empirical estimates. The findings of meta-analysis will be useful wherever an understanding of the drivers of tourism demand is critically important. Assaf et al. (2019) studied the multi-co linearity by Bayesian inference in conjugate and non-conjugate ridge regression models for tourism data set. They found that the Bayesian ridge regression generates better results than a Bayesian regression with diffused prior (Assaf et al., 2019). By downscaling global tourism simulation model, Hamilton and Tol (2007) studied the impact of climate change on tourism in Germany, Ireland, and the UK. Instead of many studies, they have provided the temporal and spatial scale results for the analysed countries. La Rocca (2014) figured out the mechanisms of cities and tourism phenomena. In his view, the city represents the "physical place where tourist desires and inhabitants needs intersect" (La Rocca, 2014). Otoo \& Kim (2018) analysed the senior travel motivations by paper frequency ranking.

Through an analysis of cause-effect relationship between sustainable tourism variables, Roxas et al. (2018) found that ecotourism creates profitable businesses and local jobs. In their analysis, the systems thinking tools and causal loop diagram were applied to determine sustainable tourism development including the tourism participants. Song et al. (2000) proposed a tourism destination preference index for UK demand. They have found that the overseas holidays influence the high amount of income elastic. In the same time, the own price elasticities also indicate that the costs of overseas holidays are a significant factor for international tourism demand. Song \& Li (2008) evaluated the tourism models demand and the forecasting methods in the literature and they have found that most of the studies had used quantitative approaches.

In the last decade, the gravity models were often used for tourism flow (Fourie \& Santana-Gallego, 2011; Santeramo \& Morelli, 2016). Through quintile regression, the estimation of the tourism demand segmentation could be achieved (Koenker, 2005; Santeramo \& Morelli, 2016). The econometric modelling is used to derive data from the obtained findings (Hall, 2012). Thus, Carey et al. (2013) studied the tourism growth in Wellington used time series analysis and econometrical regression for the cultural attraction and visitors on tourism data (e.g. number of guest arrivals, overnights, occupancy rates). The scientific literature contains several methods for environmental modelling and various elements flow by using GIS, statistics methods or artificial neural network (Ighile \& Shirakawa, 2020; Moldovan, 2020). Using statistical data (e.g. domestic trips and foreign trips, income per resident, seats on offer etc.) at NUTS2 and NUTS3 level, Zieba (2016) assessed the impact of tourism flow on demand for city theatres in Austria, between 1972 to 2011. The analysis of domestic tourism flows to 341 cities in China based on space-time analysis and spatial econometric approach was done by Yang \& Wong (2012).

Since the 1990s, Butler (1992) and Hall \& Page (2009) have argued about the importance GIS technology in Applied Geography, problem-solving, planning and decisions in tourism. Hall \& Page (2009) mentioned about the data analysis in the geographical studies on tourism at spatial scale using Geographical Information Systems (GIS) development in the geographical departments. The theory of nonparametric density estimation and bandwidth selectors for Kernel Density estimation were recently explained by Artur (2018). Correa-Quezada et al. (2020) applied the non-parametric method of Kernel density functions in order to analyze the regional growth and convergence processes in the service sector, in Ecuador, through productivity as the reference variable. Xu et al. (2017) analyzed the essential relationship established between e-commerce and tourist flow by appealing to kernel density estimation. In their enterprises they took as a model the ecommerce data of Huangshan tourism cloud platform. The research of Kokonendji \& Somé (2017, p.113) emphasized the introduction of "multivariate associated kernels with the most general bandwidth matrix". Zhu et al. (2017) based their research on the Kernel Optimization Function for sentiment word embedding in tourism domain. Asmelash \& Kumar (2019) proposed sustainability indicators for the tourism development including unidimensionality, multivariate normality, multicolinearity, construct reliability, convergent validity, discriminant validity. They underline the importance of the tourism 
indicators for the decision in tourism industry. The impacts of short-term climate variability on the touristic demand in the UK was studied by Agnew and Palutikof (2006). They analysed the climate variability on intra- and inter-annual scales using mean monthly and annual temperature, rainfall and sunshine in comparison with the domestic monthly numbers of tourist nights and international annual numbers of trips abroad. In their study, the warmer and drier conditions of 1995 contributed to benefits from tourism of up to $£ 309$ million. The total number of international visits to the UK was 4.1 million in 2015, from 48 countries. A higher amount of visits was recorded for France, US, and Germany.

One of the most used analyses in tourism and data exchanges refers to gravity models. Ciuriak et al. (2017) used gravity models to study the potential for enhancement post-Brexit of the UK's nonEU trading relationships. De Mello et al. (2002) used the equations models to investigate the tourism demand in UK and neighbour countries. In their study, Portugal, Spain, and France were highly examined through expenditure elasticities, uncompensated own-price elasticities, and uncompensated cross-price elasticities, compensated own-price elasticities, and compensated cross-price elasticities. Xing-zhu \& Qun (2013) come up with a spatial data analysis of the international tourist arrivals over 1978-2009 in China using the spatial clustering of inbound tourism flows by the "Global Moran's I" were analysed. However, the spatial scale analysis and flow models visualization are not developed enough in tourism studies. Furthermore, the UK is listed in the first five countries with tourists' source and also as one of the most visited country in the world. A study about international tourism analyses at spatial scale in UK is missing. This study aims to model tourism visits in UK using the flow lines from tourist's source to the UK and to determine the spatial scale of the tourism models through the Kernel Density function in GIS. The methodology is new and contributes to the spatial scale overview of the international visits in UK.

\section{MATERIALS AND METHODS}

\subsection{Tourism data and type of visitors in UK}

UK is mainly located on the British Islands, with exception of Republic of Ireland. The tourism statistics in UK indicate most of the visitors as holiday purpose, followed by business and friends visits. The data of holiday's visits, business visits, friend's visits, miscellaneous visits, and total visits related to 2015 in UK international arrivals belong to Office for National Statistics (ONS, 2015). The total visits per origin source, about 48 countries were analysed in this paper considering the spatial scale.

\subsection{GIS datasets}

The tourism data of visitors' source was assigned to the country of origin. Thus, ArcGIS files with vector country data were employed to process the information at a spatial scale. The centroids of each country source for tourism in UK were extracted. Four types of visits (holiday, business, friends' visits, and miscellaneous visits) were inserted into GIS database and were used to model the flow over UK. Two steps of pre-processing data have been used: (i) row tourism data analysis for each type of visitors and (ii) assign these data to the countries' centroids into ArcGIS. Furthermore, tourism flow lines and density models were generated for UK.

\subsection{Tourism flow lines}

The international visits and tourism flow directions for UK in 2015 were modelled based on 48 countries using 'XY To Line' function in ArcGIS. This function allows us to obtain the convergence lines from the tourists' sources countries over UK. To perform this operation, the centroids of the countries were extracted and geographical coordinates (latitude and longitude) were assigned to each centroid. Furthermore, the density model of the flow lines, for each type of visits was generated using Kernel Density function. This function is part of the Spatial Analyst Tools from ArcGIS, which allows a smooth surface to each polyline in base of the values of each polyline. Where the density and values of the polyline are higher, the resulted raster will have higher values in that parcels and where the polylines are missing, no data is assigned in the respective parcels. Here, we used Kernel Density for the visit types in UK. The Kernel Density function could also be used for the analysis of point data with population or information to generate the raster map (Silverman, 1986). 
The Kernel Density tool calculates the density of flow lines taking into consideration the neighbourhood around those lines. The method is based on search radius algorithm (bandwidth), which has the following formula (Eq.(1)):

$$
\text { Search radius }=0.9 \times \min \left(S D, \sqrt{\frac{1}{\ln (2)}} \times D_{m}\right) \times n^{-2}
$$

where $\mathrm{SD}$ is the standard distance; $\mathrm{D}_{\mathrm{m}}$-is the median distance; $\mathrm{n}$ is the sum of the visits field values.

\subsection{Kernel Density}

Considering the vector data of tourism flow lines, the Kernel Density was calculated for each dataset. In this function (Eq.(2)), the distance and number of tourists for that particular line are taken into account for the cartographical representation. Kernel Density represents a non-parametric approach to estimate the probability density function of random data. Being a mathematical function, Kernel Density illustrates mainly the values of the vector data. Through this tool available on ArcGIS, the classification of overlap areas could be completed. This method of Kernel Density includes the statistics for the spatial representation of the travel lines, which were represented in this study through the 'XY To Line' function. The algorithm of Kernel Density return the maximum values and the minimum values are neglected. The calculation of Kernel Density implies the normal low in statistics and the mean square deviation, where the limit of the upper bond and lower bond was fixed at $67 \%$ that is standard limit imposed by software. The calculations have been done in kilometres units and the output spatial reference is $\mathrm{km}^{2}$.

$$
f_{h}(x)=\frac{1}{n} \sum_{i=1}^{n}\left(\begin{array}{l}
n \\
k
\end{array}\right) K_{h}\left(x-x_{i}\right)
$$

where $f$ is density $f$; $\mathrm{K}$ is the kernel — a non-negative function; $\mathrm{h}>0$ is a smoothing parameter called the bandwidth; $\mathrm{x}_{1}, \mathrm{x}_{2, \ldots,}, \mathrm{x}_{\mathrm{n}}$ is univariate independent and identically distributed sample.

\section{RESULTS AND DISCUSSION}

In 2015, the number of tourists visiting the UK for holiday purposes reached 12.93 million, 1.89 million visits originating in France. Business visits registered 8.48 million in 2015, with a maximum amount of 856,457 visits for France. For friendly visits, there were 9.83 million tourists in UK related to 2015 and 1.12 million belong to France. The miscellaneous visits accounted for 2.72 million, 356,443 of which from the Republic of Ireland. The total number of visits in 2015 reached33.98 million, 4.17 million from France. The countries from which most visitors originate are mainly located in continental Europe: France (4.17 million), Germany (3.24 million), Netherlands (1.89 million), Italy (1.79 million) Republic of Ireland (1.63 million), Belgium (1.17 million), as well as the US (3.26 million) (ONS, 2015). Looking at the types of visitors, holiday visits have the tourists originating from Europe, North and South America, Australia, and Asia (Fig.1). About four countries from Africa contribute to the international holiday visits in UK. The business visits recorded higher values (over 600,000 visits) for the European countries and the US (Fig.2), while the lower values (below 10,000 visits) were recorded for Mexico, Pakistan, Thailand, and some countries from Africa. Friendly visits amount aremuch more diversified in the UK, including higher values (above 400, 000 visits) from the US, Western Europe, and Australia. Five countries from Africa (Morocco, Tunisia, South Africa, Nigeria, and Egypt) and only Brazil and a French colonial state from South America contributed during 2015 at the international friends' visits in UK (Fig.3). Kernel Density tool was used to generate the density of the converged flow lines of the international visits to the UK. For holiday visits, a very high density was obtained for European countries (France, Italy, Germany) and for US (Fig.6a), while high values could be observed from Australia, Canada, China, Western and Central Europe as well. 


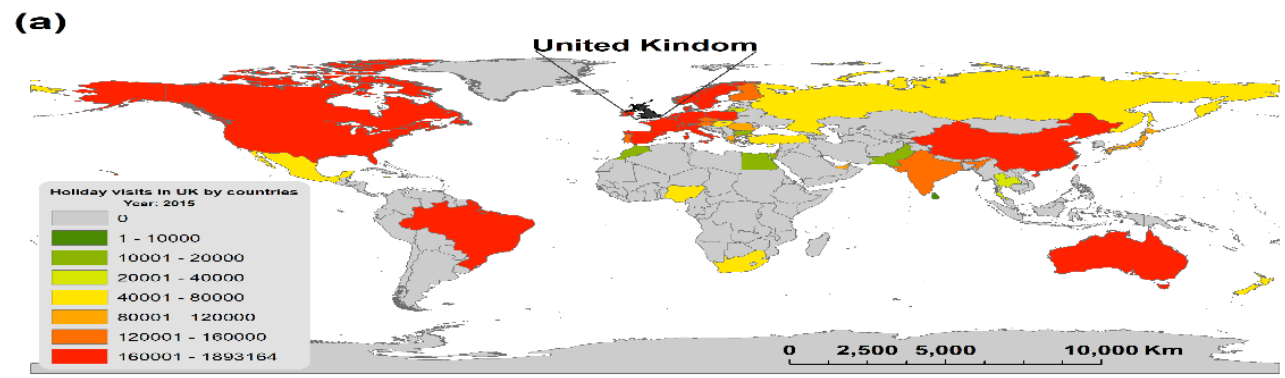

(b)

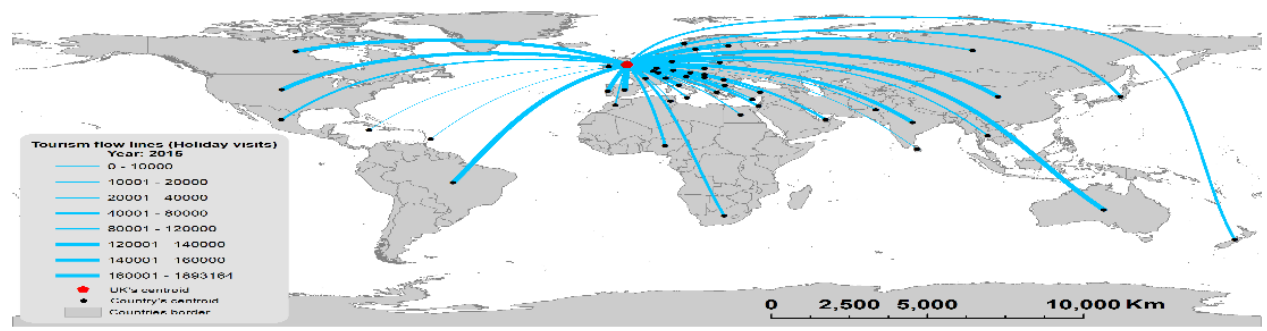

Fig. 1. (a) Holidays visits (2015) in UK by country origin. (b) Tourism flow lines (2015) from the origin countries to UK for the holidays visits.

(a)

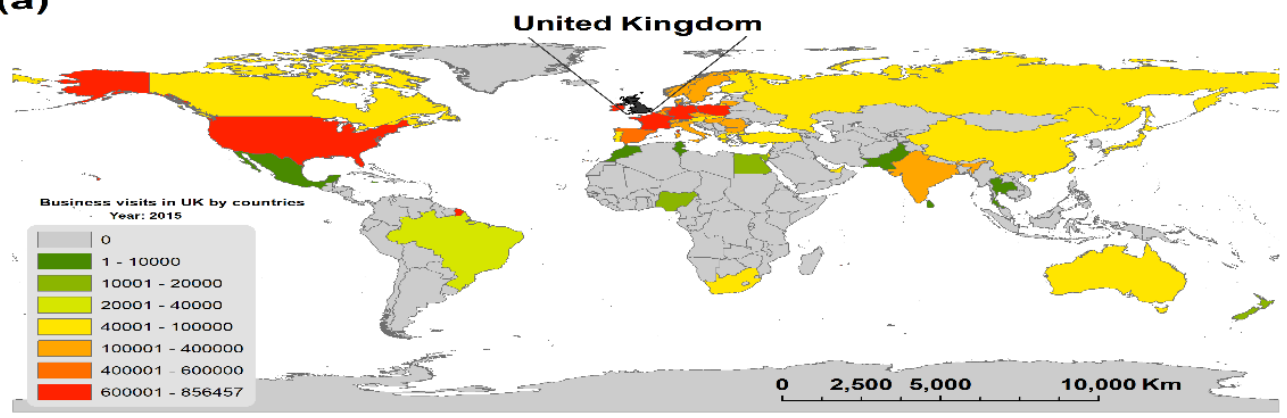

(b)

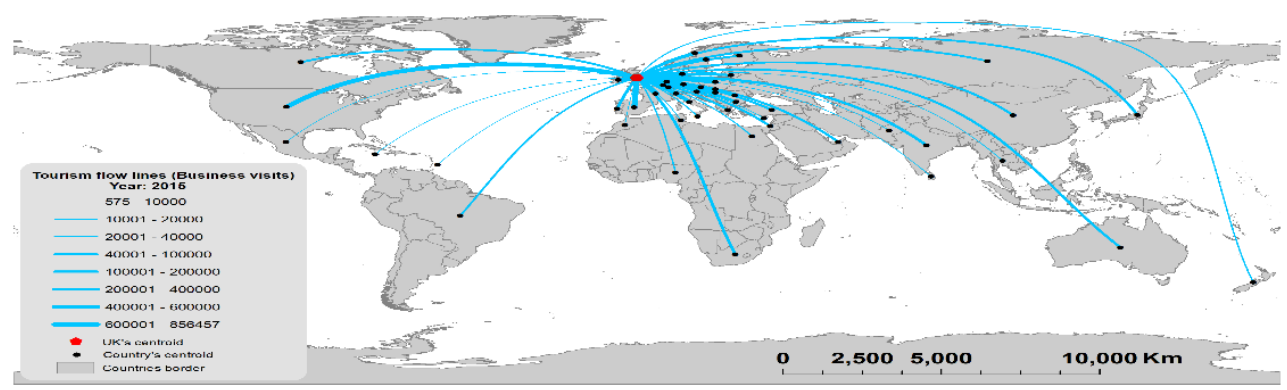

Fig. 2. (a) Business visits (2015) in UK by country origin. (b) Tourism flow lines (2015) from the origin countries to UK for the business visits. 
(a)

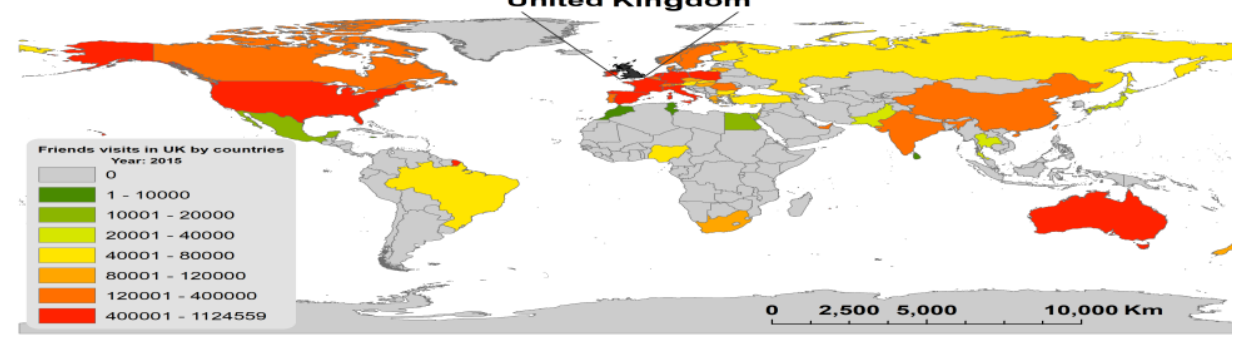

(b)

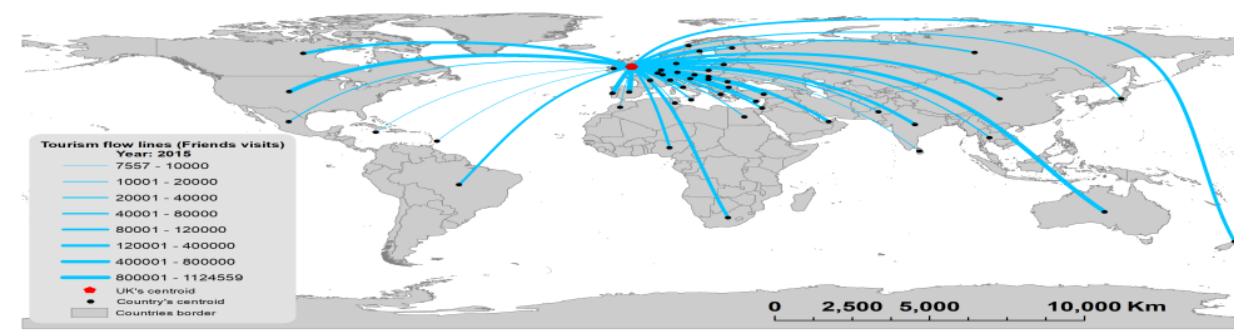

Fig.3. (a) Friends visits (2015) in UK by country origin. (b) Tourism flow lines (2015) from countries of origin to the UK for friends visits.

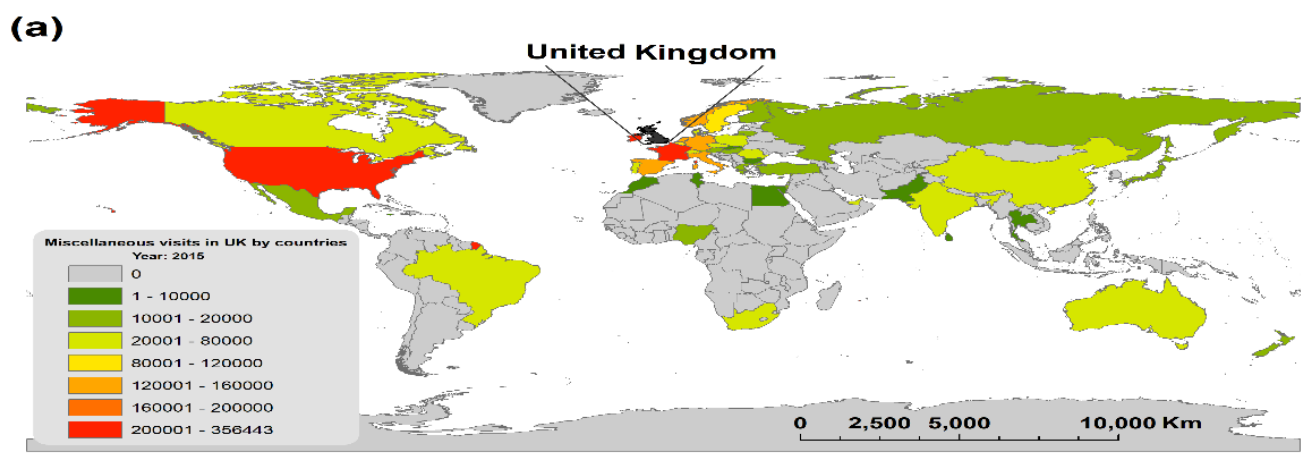

\section{(b)}

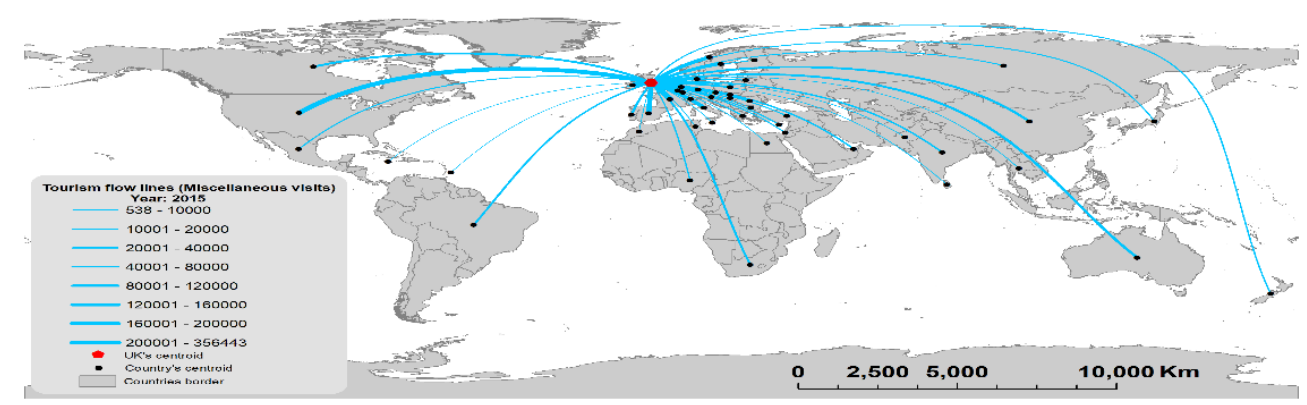

Fig.4. (a) Miscellaneous visits (2015) to the UK by country origin. (b) Tourism flow lines (2015) from the origin countries to the UK for miscellaneous visits. 


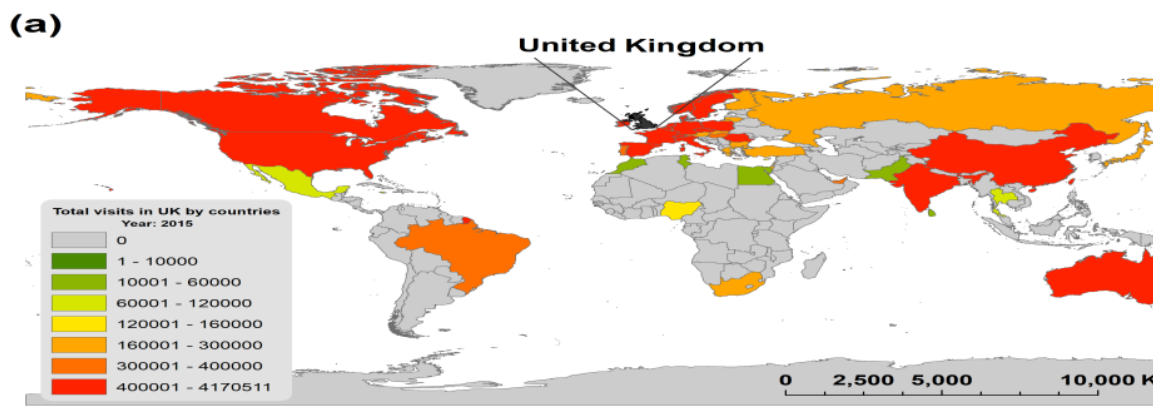

(b)

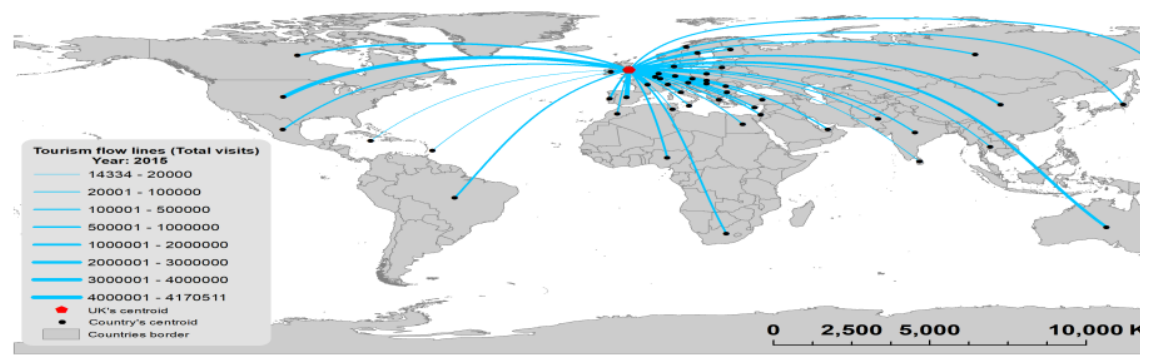

Fig.5. (a) Total visits (2015) to the UK by country of origin. (b) Tourism flow lines (2015) from the countries of origin to the UK for total visits.

Miscellaneous visits had higher values (more than 200,000 visits) for France and the US. Fig.4 indicates low values around the world, with much implication for the European countries. At a global level, the total visits to the UK in 2015 are significant for France, Italy, US, Australia, China, India, and other European countries (Fig. 5). The density model for business visits had extremely high values in the proximity of UK, in Belgium and Netherlands, while high values are from the US, Romania, Italy, and Central European countries (Fig.6b). The friendly visits flow model indicates a surprisingly high density from Belgium and France, while the high density is shown from US, Australia, and Central Europe (Fig.6c). Miscellaneous visits have high densities from the Republic of Ireland, and from the proximity of the UK border. High density values for the miscellaneous visits were calculated from US, Canada, China, Australia, Central, Southern, and Northern Europe (Fig.6d). Medium, low, and very low densities were mainly found for all types of visits from Mexico, Central America, Brazil, African countries, India, New Zealand, Japan, the Middle East, and Russia.

Tourism flow models density.

Table 1.

\begin{tabular}{lccccc}
\hline $\begin{array}{c}\text { Density } \\
\text { classes }\end{array}$ & $\begin{array}{c}\text { Holiday visits } \\
(\text { area \%) }\end{array}$ & $\begin{array}{c}\text { Business visits } \\
(\text { area \%) }\end{array}$ & $\begin{array}{c}\text { Friendly visits } \\
\text { (area \%) }\end{array}$ & $\begin{array}{c}\text { Miscellaneous } \\
\text { visits (area \%) }\end{array}$ & $\begin{array}{c}\text { Total visits } \\
\text { (area \%) }\end{array}$ \\
\hline Very low & 19.57 & 27.46 & 17.60 & 35.77 & 10.34 \\
Low & 23.86 & 36.33 & 34.89 & 48.02 & 19.37 \\
Medium & 43.93 & 30.92 & 38.98 & 16.10 & 44.88 \\
High & 10.68 & 5.11 & 8.42 & 0.11 & 20.51 \\
Very High & 1.95 & 0.17 & 0.11 & 0.00 & 4.91 \\
\hline
\end{tabular}

Source: GIS statistics. Note: the values consider only the model density for the UK, without nil values. 


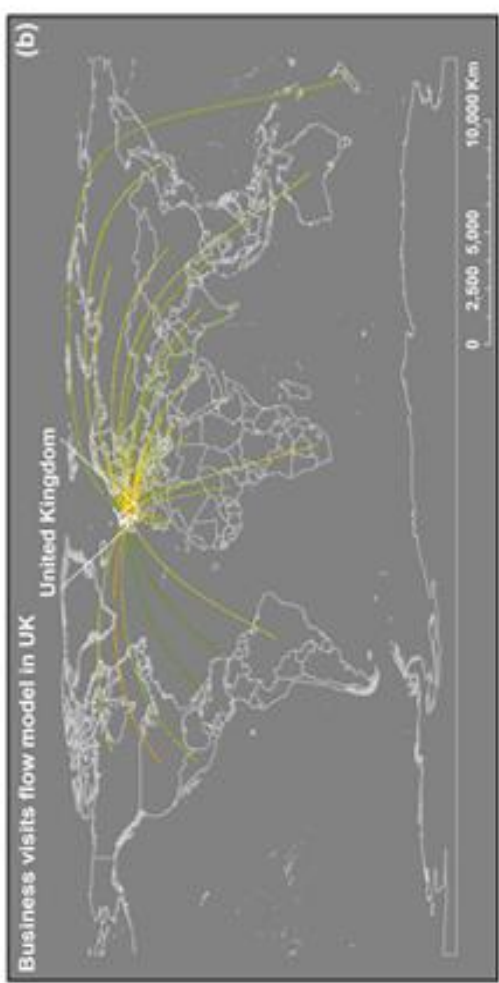

(e)

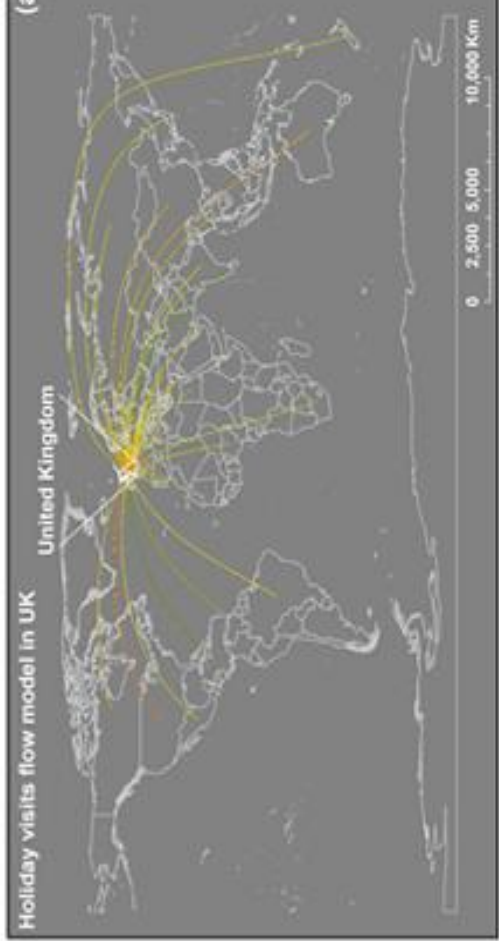

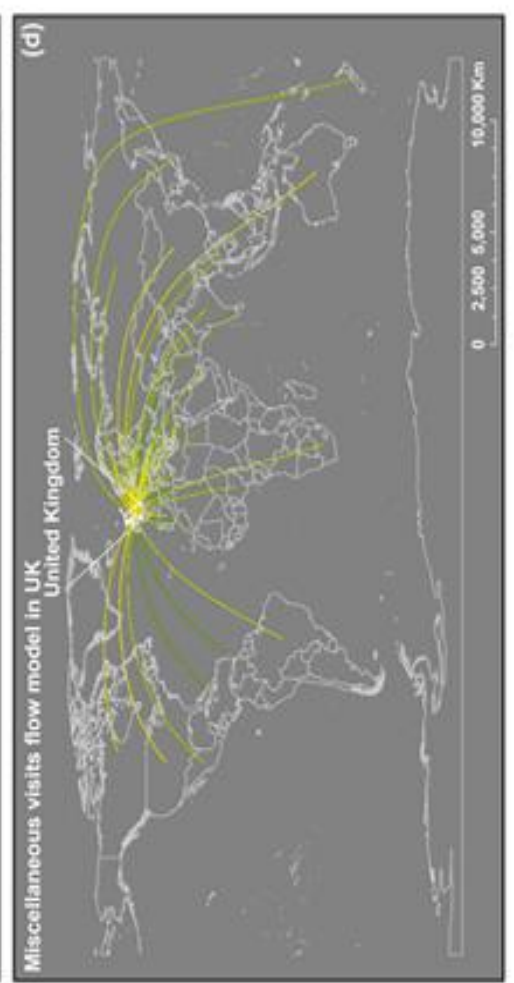

(5)

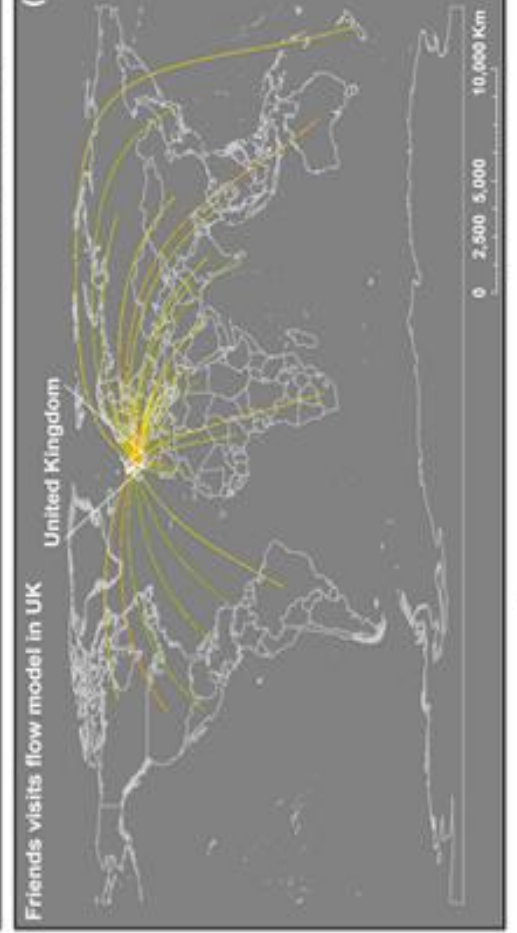

壱窇

অ

एक

1 要

อ음

号总

17

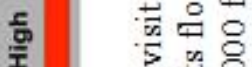

?

in 8

뇽

킁 -

突总 8

혚 몸

ఏ

क्ष

E $\rightarrow$

药

(త) 8

vi

ํํำำำ

$\Xi$ 已

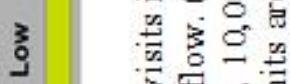

品自

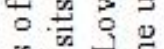

영도

3.

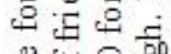

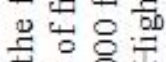

- 8 =

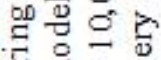

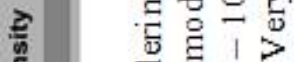

埚

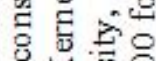

焉 8

능용

ए 30

zan

3 它

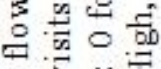

$5 \ddot{\circ}$

为 is ob

害寻8

1.58

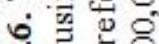

부은 


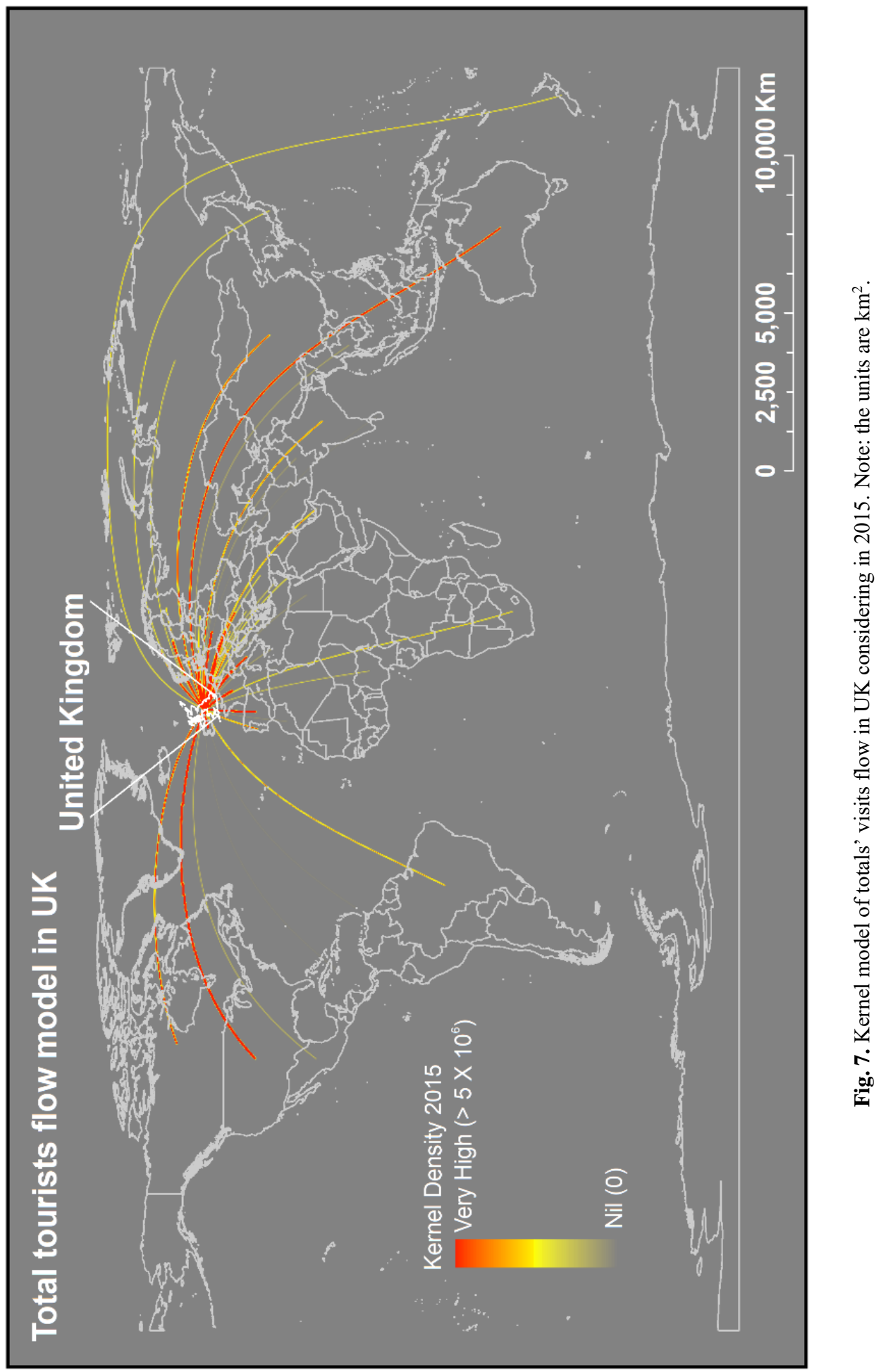


The total UK visits in 2015 contributed to very high density in western Europe and the US, while high densities were mainly found in Central European countries, Canada, Brazil, China, the Middle East (United Arab Emirates), India, and Australia. The medium density was depicted over central Europe, Mexico, Nigeria, Russia, New Zealand, Egypt, Israel, Turkey, and Japan. Low and very low densities were found in Central America, Sri Lanka, and North African countries. Fig.7 illustrates the density model of the total UK visits. The statistical analysis of the density models indicates $1.95 \%$ of very high density in area for the holiday visits, while the very high density area for business visits, friendly visits, and miscellaneous visits, the values are $0.17 \%, 0.11 \%$, respective $0 \%$. The medium density has higher values for holiday visits $(43.93 \%)$ and friends' visits $(38.98 \%)$. business visits $(36.33 \%)$ and miscellaneous visits $(48.02 \%)$ have higher values in the low density class. The higher area of the density model for the total visits is representative for medium density class, with $44.88 \%$, followed by high density class $(20.51 \%)$ and low density class $(19.37 \%)$. Tab.1 reports the statistical values of the density models for each type of visit to the UK in 2015.

Overall, the proposed methodology depicts visit flow lines and density model in this study reflects the GIS technology implication for the spatial distribution of tourists flow. The applied GIS functions utilized to generate the flow lines and Kernel Density for UK visits contributed to obtain areas with different classes of density global scale. The importance of our model impacts not only the current study, but may also contribute to tourism data analysis at a spatial scale, analytics, and statistics in the field of tourism, considering that the topic of tourism could be also developed in this direction. Number of visitors and proximity of tourists' source influence the model proposed by us. Thusly, the pattern of Kernel Density indicates the flow from European countries to the UK as high and very high density. Countries located at further away (e.g. US, China, Australia) have high and very high density of visits flow due to the higher population and availability to travel for extra-continental visits. As resulted from the models, the holiday visits recorded in 2015 higher values for both European tourists' source and other continents. The usefulness of these models is that they can help policy-makers develop new services for such tourists, improve transport infrastructure during various periods of year and plan the strategies to attract tourist from other countries.

This survey demonstrates how international visits could be represented at a spatial scale, considering flow lines and density models. The methodology was applied on UK data and it combines tourist information with spatial statistics of source countries. Thusly, the geospatial analysis was developed in this study to observe the convergences, density and intensity of the flow lines models. The improvement and continuity of our approach could be focused on future predictions and density calculations. As a limitation, the proposed model does not take into consideration worldwide touring, as the flow lines are directly connected to the tourists' source. This procedure contains the analysis of data in the attributes tables of layers into ArcGIS. The dynamic tourism flow, including visits in other countries before UK, could be considered a desired model, but such as model is currently difficult to implement for a high number of countries (e.g. 48 for this study). The exploration of tourism flows, through multiple countries before the final destination, by oriented programming and GIS technology, may represent a significant improvement for both data analysis and spatial displacement.

The advantages of the proposed model in this study refers to the ease of identifying direct connections between origin and destination countries of tourists, highlighting the countries with higher amount of visitors source, and evaluating the density of tourist flow at spatial scale. For this reason, the integration of tourism data into a GIS database and further analyses might provide the required models based on automatic and validated tools.

\section{CONCLUSIONS}

Tourism visits in UK during 2015 were analysed in this paper. The origin of visitors and their purpose (holiday, business, friendly visits, miscellaneous) were analysed at spatial scale in order to generate a tourism flow model. Using the GIS technology, the flow lines and Kernel Density models of the international visits to the UK served to represent the tourism fluxes. The flow models indicate higher concentration for Europe density, while in the case of more distant countries, such as Australia, 
New Zealand, Japan, Brazil, and Canada, the distance factor influences the total visits flows to the UK. Consequently, the Kernel Density is higher in Western Europe and in the US.

The present study is a way to represent the touristic data and international flow visits on the world map. In fact, the proposed model is a contribution at spatial scale using UK data for 2015. The exploration of tourism flows using GIS software with specific functions such as XY To Line' and 'Kernel Density' contributes with advantages for tourism strategies and future tourism planning. For instance, the general movement of tourists and tourism flow lines indicate the main route travel and further travel infrastructure and journey could be planned. In addition, the high demand for tourism is reflected into the transport systems and the social-economic development. In this context, the tourism flow models may help to develop new transports infrastructure or new journey programs in a certain period of year. Thus, the Kernel Density function applied in this study contributes to the better management of big tourism data, future strategies and development plans, both for countries close to the UK and worldwide.

\section{Acknowledgments}

The authors would like to extend their gratitude to the UK Office for National Statistics for tourism data. This paper was devised by the authors as an independent initiative and did not receive any grants or funds from any university or agency whatsoever.

\section{REFERENCES}

Agnew, M. D. \& Palutikof, J.P. (2006) Impacts of short-term climate variability in the UK on demand for domestic and international tourism. Climate Research, 31, 109-120.

Artur, G. (2018) Nonparametric Kernel Density Estimation and Its Computational Aspects. Springer Studies in Big Data, ISBN 978-3-319-71688-6.

Asmelash, A.G. \&Kumar, S. (2019) Assessing progress of tourism sustainability: Developing and validating sustainability indicators. Tourism Management, 71, 67-83.

Assaf, A.G., Tsionas, M. \&Tasiopoulos, A. (2019) Diagnosing and correcting the effects of multicollinearity: Bayesian implications of ridge regression. Tourism Management 71, 1-8.

Butler, R.W. (1992) Alternative tourism: the thin edge of the wedge. In V. L. Smith, \& W. R. Eadington (Eds.), Tourism alternatives: potentials and problems in the development of tourism (pp. 302-321). Philadelphia: University of Pennsylvania Press.

Carey, S., Davidson, L. \&Sahli, M. (2013) Capital City Museums and Tourism Flows: an Empirical Study of the Museum of New Zealand Te Papa Tongarewa. International Journal of Tourism Research, 15(6), 554-569.

Ciuriak, D., Siauw-Soegiarto, F.\& SUN, S.Z. (2017) Quantifying the UK's Post-Brexit Export Potential: A Gravity Model Analysis. Research Report.

Correa-Quezada, R., Cueva-Rodríguez, L., Álvarez-García, J. \& del Río-Rama, M.D.L.C. (2020) Application of the Kernel Density Function for the Analysis of Regional Growth and Convergence in the Service Sector through Productivity. Mathematics, 8(1234), 1-20.

De Mello, M., Pack, A. \& Sinclair, M.T. (2002) A system of equations model of UK tourism demand in neighbouring countries.Applied Economics, 34(4), 509-521, DOI: 10.1080/00036840110049310

Divisekera, S. (2003) A model of demand for international tourism. Annals of Tourism Research, 30(1), 31-49.

Fourie, J. \& Santana-Gallego, M. (2011) The impact of mega-sport events on tourist arrivals. Tourism Management, 32(6), 1364-1370.

Hall, C. M. \& Page, S.J. (2009) Progress in Tourism Management: From the geography of tourism to geographies of tourism - A review. Tourism Management, 30, 3-16.

Hall, C.M. (2012) Spatial analysis: A critical tool for tourism geographies. In J. Wilson (Ed.), The Routledge handbook of tourism geographies (pp. 163-173). London: Routledge.

Hamilton, J.M. \& Tol, R.S.J. (2007) The impact of climate change on tourism in Germany, the UK and Ireland: a simulation study. Reg. Environ. Change, 7, 161-172. 
Ighile, E.H. \& Shirakawa, H. (2020) A study on the effects of land use change on flooding risks in Nigeria. Geographia Technica, 15(1), 91-101.

Koenker, R. (2005) Quantile Regression. Cambridge University Press, New York, NY 10011-4211, USA. ISBN 0-521-84573-4

Kokonendji, C.C. \& Somé, S.M. (2018) On multivariate associated kernels to estimate general density functions. Journal of the Korean Statistical Society, 47(1), 112-126.

La Rocca, R.A. (2014) The Role of Tourism in Planning the Smart City. Tema. Journal of Land Use, Mobility and Environment, 7(3), 269-283. DOI: http://dx.doi.org/10.6092/1970-9870/2814

Moldovan, I.F. (2020) Calculation of the river flow with different probabilities of occurrence using artificial neural network. Geographia Technica,15(1), 162-172.

Office For National Statistics (ONS). (2015) Visits, nights and spending in UK: by purpose of visit and country of residence 2015 .

Otoo, F.E. \& Kim, S.S. (2018) Analysis of studies on the travel motivations of senior tourists from 1980 to 2017 : progress and future directions. Current Issues in Tourism, DOI: 10.1080/13683500.2018.1540560.

Peng, B., Song, H., Crouch, G.I. \& Witt, S.F. (2014) A Meta-Analysis of International Tourism Demand Elasticities. Journal of Travel Research, 54(5), 611-633. Doi:10.1177/0047287514528283.

Roxas, F.M.Y., Rivera, J.P.R. \& Gutierrez, E.L.M. (2018) Framework for creating sustainable tourism using systems thinking. Current Issues in Tourism, DOI: 10.1080/13683500.2018.1534805.

Santeramo, F.G. \& Morelli, A. (2016) Modelling tourism flows through gravity models: a quantile regression approach. Current Issues in Tourism, 19(11), 1077-1083.

Silverman, B.W. (1986) Density Estimation for Statistics and Data Analysis. New York: Chapman and Hall.

Song, H. \& Li, G. (2008) Tourism demand modelling and forecasting-A review of recent research. Tourism Management, 29, 203-220.

Xing-Zhu, Y.\& Qun, W. (2013) Exploratory Space-time Analysis of Inbound Tourism Flows to China Cities. International Journal of Tourism Research, 16 (3), 303-312. DOI: 10.1002/jtr.1932.

Xu, J., Liang, C., Lu, W., Zhao, S. \& Zhang, H. (2017) Analysis of e-commerce based on data flow kernel density estimation in the Huangshan tourism cloud platform. In 2017 IEEE 2nd International Conference on Big Data Analysis (ICBDA)( (pp. 63-67). IEEE.

Yang, Y. \& Wong, K.K.F. (2012) A Spatial Econometric Approach to Model Spillover Effects in Tourism Flows. Journal of Travel Research, 51(6), 768-778.

Zieba, M. (2016) Tourism flows and the demand for regional and city theatres in Austria. Journal of Cultural Economics, 40(2), 191-221.

Zhu, L., Li, W., Guo, K., Shi, Y. \& Zheng, Y. (2017) The tourism-specific sentiment vector construction based on kernel optimization function. Procedia computer science, 122, pp.1162-1167. 